\title{
NKG2D Signaling Leads to NK Cell Mediated Lysis of Childhood AML
}

\section{Patrick Schlegel, Kerstin Ditthard, Peter Lang, Markus Mezger, Sebastian Michaelis, Rupert Handgretinger, and Matthias Pfeiffer}

Department of Hematology and Oncology, University Children's Hospital Tübingen, University of Tübingen, Hoppe-Seyler-Straße 1, 72076 Tübingen, Germany

Correspondence should be addressed to Peter Lang; peter.lang@med.uni-tuebingen.de

Received 17 December 2014; Revised 9 June 2015; Accepted 16 June 2015

Academic Editor: David Kaplan

Copyright (C) 2015 Patrick Schlegel et al. This is an open access article distributed under the Creative Commons Attribution License, which permits unrestricted use, distribution, and reproduction in any medium, provided the original work is properly cited.

Natural killer cells have been shown to be relevant in the recognition and lysis of acute myeloid leukemia. In childhood acute lymphoblastic leukemia, it was shown that HLA I expression and KIR receptor-ligand mismatch significantly impact ALL cytolysis. We characterized 14 different primary childhood AML blasts by flow cytometry including NKG2D ligands. Further HLA I typing of blasts was performed and HLA I on the AML blasts was quantified. In two healthy volunteer NK cell donors HLA I typing and KIR genotyping were done. Blasts with high NKG2D ligand expression had significantly higher lysis by isolated NK cells. Grouping the blasts by NKG2D ligand expression led to a significant inverse correlation of HLA I expression and cytolysis in NKG2D low blasts. Furthermore, a significant positive correlation of NKG2D ligand expression and blast cytolysis was shown. No impact of KIR ligand-ligand mismatch was found but a significantly increased lysis of homozygous C2 blasts by KIR2DL1 negative NK cells (donor B) was revealed. In conclusion, NKG2D signaling leads to NK cell mediated lysis of childhood AML despite high HLA I expression.

\section{Introduction}

Despite intensification of therapy and the use of new chemotherapeutic agents, one-third to one-half of children with acute myeloid leukemia (AML) experience relapse $[1,2]$. Hematopoietic stem cell transplantation (HSCT) and natural killer (NK) cell transfer as cellular targeted treatment strategy have been shown to increase relapse-free survival in childhood AML [3]. Natural killer cells are cytotoxic lymphocytes that play an important role in antitumor immunity [4]. Reduced NK cell count, impaired NK cell function, and the prognostic relevance in leukemia evidence the involvement of NK cells in leukemia immunosurveillance [5-7]. Moreover, evidence for the ability of NK cells to recognize and eliminate leukemic blasts in humans has been provided by clinical HSCT trials $[8,9]$. NK cells are regulated by activating, inhibitory and co-receptor signaling. The activation comprises the principles of "missing self" and "induced self," implying that NK cells kill target cells with low or absent expression of HLA class I and stress-induced expression of ligands for activating NK cell receptors as well as costimulatory receptors [10]. In pediatric ALL, susceptibility to NK cell mediated recognition and cytolysis is correlated to the quantity of HLA I expression and KIR receptorligand (RL) mismatch $[11,12]$. However, little is known about childhood AML in regard to NK cell mediated antitumor effects including quantity of HLA I expression as well as the prostimulatory signaling of DNAM-1 and NKG2D. In addition, whereas the relevance of NKG2D signaling in NK cell immunosurveillance and escape mechanism of adult AML is well established, its role in childhood AML is unknown [13]. To address the question of which activating and inhibitory signals determine NK cell mediated recognition and cytolysis in childhood AML, we analyzed primary childhood AML blasts and their susceptibility to NK cell mediated cytolysis in a HLA mismatched setting, taking into account major features of NK cell regulation.

\section{Materials and Methods}

The study was authorized by the ethical institutional review board of the University of Tübingen, Germany. The blasts 
TABLE 1

\begin{tabular}{|c|c|c|c|c|c|}
\hline Healthy donors & HLA type & \multicolumn{2}{|c|}{ HLA I ligand } & Corresponding inhibitory KIR & KIR mismatch \\
\hline Donor A & $\mathrm{C} 1 / \mathrm{C} 2$ & bw $6^{+} / \mathrm{bw} 4^{+}$ & $\mathrm{cw}^{+} / \mathrm{cw} 4^{+}$ & KIR2DL1, KIR2DL2/3, KIR3DL1 & - \\
\hline Donor B & $\mathrm{C} 1 / \mathrm{C} 1$ & bw $6^{+} / \mathrm{bw} 4^{+}$ & $\mathrm{cw}^{+} / \mathrm{cw}^{+}$ & KIR2DL2/3, KIR3DL1 & KIR2DL1 \\
\hline \multicolumn{6}{|l|}{ Childhood AML blasts } \\
\hline AML-1 FAB M0 & $\mathrm{C} 1 / \mathrm{C} 1$ & bw $6^{+} / \mathrm{bw} 4^{+}$ & $\mathrm{cw3}^{+} / \mathrm{cw}^{+}$ & KIR2DL2/3, KIR3DL1 & KIR2DL1 \\
\hline AML-2 FAB M0 & $\mathrm{C} 2 / \mathrm{C} 2$ & bw $6^{+} / \mathrm{bw} 4^{+}$ & $\mathrm{cw} 4^{+} / \mathrm{cw} 4^{+}$ & KIR2DL1, KIR3DL1 & KIR2DL2/3 \\
\hline AML-3 FAB M2 & $\mathrm{C} 1 / \mathrm{C} 1$ & bw $4^{+} / \mathrm{bw} 4^{+}$ & $\mathrm{cw3}^{+} / \mathrm{cw3}^{+}$ & KIR2DL2/3, KIR3DL1 & KIR2DL1 \\
\hline AML-4 FAB M2 & $\mathrm{C} 1 / \mathrm{C} 2$ & bw6 $^{+} / \mathrm{bw}^{+}$ & $\mathrm{cw}^{+} / \mathrm{cw} 4^{+}$ & KIR2DL1, KIR2DL2/3 & KIR3DL1 \\
\hline AML-5 FAB M4 & $\mathrm{C} 2 / \mathrm{C} 2$ & bw $6^{+} / \mathrm{bw} 4^{+}$ & $\mathrm{cw} 4^{+} / \mathrm{cw} 4^{+}$ & KIR2DL1, KIR3DL1 & KIR2DL2/3 \\
\hline AML-6 FAB M4 & $\mathrm{C} 1 / \mathrm{C} 2$ & bw $6^{+} / \mathrm{bw} 4^{+}$ & $\mathrm{cw}^{+} / \mathrm{cw} 4^{+}$ & KIR2DL1, KIR2DL2/3, KIR3DL1 & - \\
\hline AML-7 FAB M5 & $\mathrm{C} 2 / \mathrm{C} 2$ & bw6 $^{+} / \mathrm{bw}^{+}$ & $\mathrm{cw} 4^{+} / \mathrm{cw} 4^{+}$ & KIR2DL1 & KIR2DL2/3, KIR3DL1 \\
\hline AML-8 FAB M5 & $\mathrm{C} 1 / \mathrm{C} 2$ & bw $4^{+} / \mathrm{bw} 4^{+}$ & $\mathrm{cw}^{+} / \mathrm{cw} 4^{+}$ & KIR2DL1, KIR2DL2/3, KIR3DL1 & - \\
\hline AML-9 FAB M5 & $\mathrm{C} 1 / \mathrm{Cl}$ & bw $6^{+} / \mathrm{bw} 4^{+}$ & $\mathrm{cw3}^{+} / \mathrm{cw}^{+}$ & KIR2DL2/3, KIR3DL1 & KIR2DL1 \\
\hline AML-10 FAB M5 & $\mathrm{C} 1 / \mathrm{C} 1$ & $\mathrm{bw}^{+} / \mathrm{bw}^{+}$ & $\mathrm{cw3}^{+} / \mathrm{cw3}^{+}$ & KIR2DL2/3 & KIR2DL1, KIR3DL1 \\
\hline AML-11 FAB M5b & $\mathrm{C} 1 / \mathrm{C} 2$ & bw $6^{+} / \mathrm{bw} 4^{+}$ & $\mathrm{cw}^{+} / \mathrm{cw}^{+}$ & KIR2DL1, KIR2DL2/3, KIR3DL1 & - \\
\hline AML-12 FAB M6 & $\mathrm{C} 1 / \mathrm{C} 2$ & $\mathrm{bw}^{+} / \mathrm{bw}^{+}$ & $\mathrm{cw}^{+} / \mathrm{cw} 4^{+}$ & KIR2DL1, KIR2DL2/3 & KIR3DL1 \\
\hline AML-13 FAB M6 & $\mathrm{C} 1 / \mathrm{C} 1$ & bw $6^{+} / \mathrm{bw} 4^{+}$ & $\mathrm{cw3}^{+} / \mathrm{cw3}^{+}$ & KIR2DL2/3, KIR3DL1 & KIR2DL1 \\
\hline AML-14 FAB M6 & $\mathrm{C} 2 / \mathrm{C} 2$ & bw $6^{+} / \mathrm{bw} 4^{+}$ & $\mathrm{cw} 4^{+} / \mathrm{cw} 4^{+}$ & KIR2DL1, KIR3DL1 & KIR2DL2/3 \\
\hline
\end{tabular}

used in the experiments were isolated from patients who were treated at the Department of Pediatric Hematology/Oncology of the University Children's Hospital Tübingen, Germany. Patients and healthy donors gave informed consent.

\subsection{HLA I Typing of Cryopreserved Childhood AML Blasts and} Healthy Donors. HLA I typing of the selected cryopreserved AML blasts was provided by the institute for transplant immunology and immunohematology (see Table 1).

2.2. KIR Genotyping of Healthy Donors. Donor A, KIR A haplotype was KIR2DL1, KIR2DL3, KIR2DL4, KIR2DS4, KIR3DL1, KIR3DL2, and KIR3DL3. Donor B, KIR B haplotype was KIR2DL2, KIR2DS2, KIR2DL4, KIR2DS4, KIR3DL1, KIR3DS1, KIR3DL2, and KIR3DL3.

KIR genotype of donor A resulted in B0 score and KIR genotype of donor B resulted in B3 score (http://www.ebi .ac.uk/cgi-bin/ipd/kir/donor_b_content.cgi) [14]. Amplification of KIR genes was performed using KAPA Sybr Fast qPCR Master Mix for iCycler (PEQLAB, Erlangen, Germany). After an initial denaturation step for $20 \mathrm{~s}$ at $95^{\circ} \mathrm{C}, 32$ PCR cycles with $3 \mathrm{~s}$ at $95^{\circ} \mathrm{C}$ and $20 \mathrm{~s}$ at $64^{\circ} \mathrm{C}$ were run on the CFX96 realtime PCR detection (Bio-Rad, Hercules, CA, USA) system as published [15].

2.3. Preparation of $\mathrm{CD} 6^{+} \mathrm{CD}^{-} \mathrm{NK}$ Effector Cells. Peripheral blood mononuclear cells (PBMCs) were isolated from peripheral whole blood of two healthy volunteer donors by density gradient centrifugation using Biocoll separating solution (Biochrom GmbH, Berlin, Germany). CD56 ${ }^{+} \mathrm{CD}^{-}$ NK cells were isolated from PBMCs by immunomagnetic $\mathrm{CD} 6^{+}$selection using microbeads (Miltenyi Biotech, Bergisch Gladbach, Germany), followed by $\mathrm{CD}^{+}$depletion using dynabeads (Invitrogen, Carlsbad, CA, USA) [16].
2.4. Leukemic Blasts. Acute myeloid leukemia cells were obtained from pediatric patients from bone marrow or peripheral blood at the time of diagnosis or relapse after informed consent of the legal guardians. Diagnoses were childhood AML (FAB classification M0, M2, M4, M5, M5b, and M6). AML blasts were cryopreserved immediately after diagnosis (purity $>80 \%$ ). The relative proportion of the primary childhood AML blasts was reliably determined by flow cytometry, using an extensive immunophenotyping leukemia panel including the markers CD45, CD33, CD34, CD117, HLADR, AC133, MPO, CD15, CD13, CD7, CD17, Glycophorin A, CD56, CD1a, CD3, CD4, CD8, CD5, CD64, w65, CD41a, CD14, CD15, CD61, CD2, CD42, CD79b, CD19, CD10, CD20, CD22, Kappa, Lambda, TdT, and W6/32. AML blast samples below $80 \%$ purity of blasts were considered ineligible and excluded.

2.5. Phenotypic Characterization of Childhood AML Blasts. Flow cytometry was performed according to standard protocols on a 4-color FACSCalibur flow cytometer using CellQuest software for data acquisition (Becton Dickinson, Heidelberg, Germany). AML blasts were not distinguished from healthy leukocytes by any marker but purity of blasts > $80 \%$ was a prerequisite. The listed antibodies were used in saturating concentrations: mouse anti-human antibodies CD1la ( $\left.\operatorname{IgG}_{2 \mathrm{a}}, \mathrm{PE}\right), \mathrm{CD} 18$ ( $\operatorname{IgG}_{1}$, FITC), CD48 (IgM, FITC), CD50 (IgG $1, P E)$, CD54 (IgG $2 \mathrm{~b}, \mathrm{PE}), \mathrm{CD} 58$ ( $\operatorname{IgG}_{2 \mathrm{a}}$, PE), CD95 (IgG 1 , FITC), and CD112 (IgG, FITC) (Becton Dickinson); MICA and MICB ( $\left.\operatorname{IgG}_{2 \mathrm{a}}, \mathrm{APC}\right)$ and HLAABC (IgG ${ }_{2 a}$, unlabeled) (Biolegend, San Diego, CA, USA); CD155 ( $\operatorname{IgG}_{1}$, FITC) (eBioscience, San Diego, CA, USA); unlabeled ULBP1 (Z-9, IgG $2 \mathrm{a})$, ULBP2 (E16, IgG $2 \mathrm{a})$, ULBP3 $\left(2 \mathrm{~F} 9, \mathrm{IgG}_{2 \mathrm{a}}\right)$, and ULBP4 $\left(6 \mathrm{E} 6, \mathrm{IgG}_{2 \mathrm{~b}}\right)$ (Santa Cruz, Dallas, TX, USA); HLA-E (IgG ${ }_{1}$, unlabeled) (Exbio, Praha, Czech Republic); polyclonal goat anti-mouse $\left(\mathrm{Gt} \mathrm{F}\left(\mathrm{ab}^{\prime}\right)_{2}\right.$, FITC) 


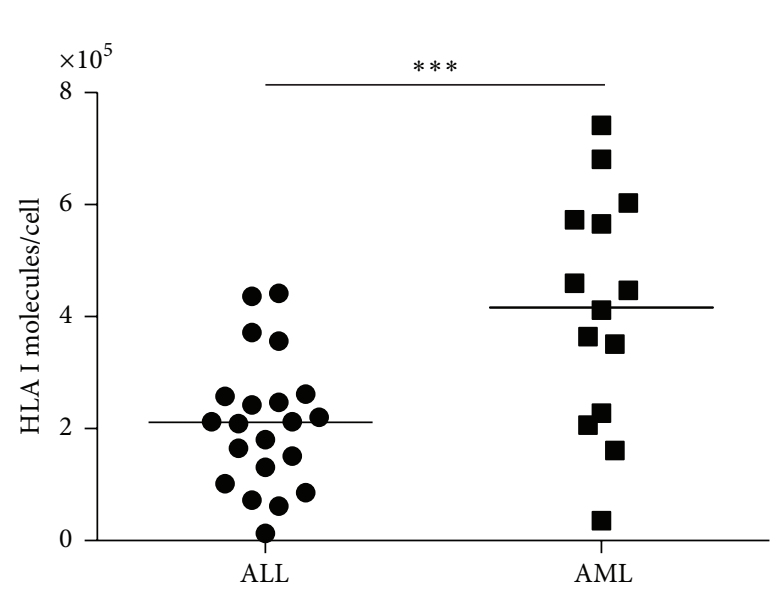

(a)

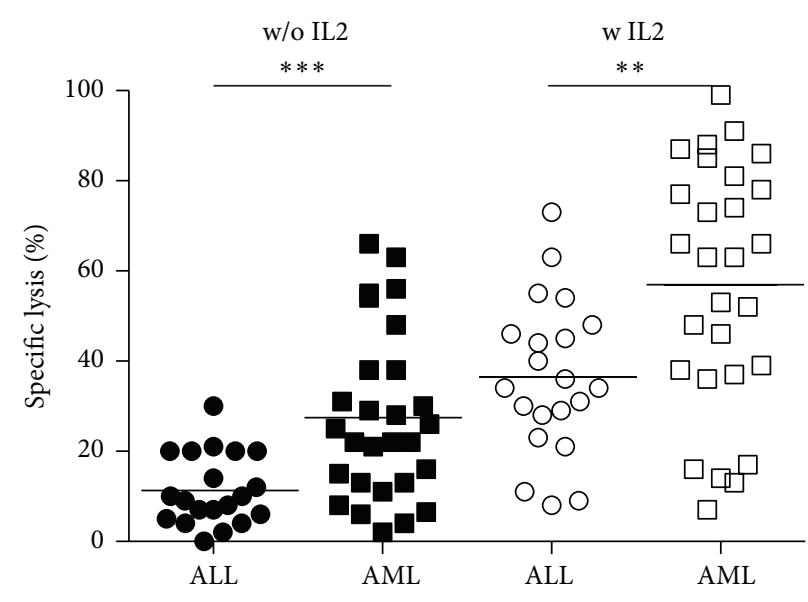

(b)

FIGURE 1: Quantitative HLA I expression (a) in primary childhood ALL and AML blasts measured by Qifikit (Dako). HLA I molecules/cell mean $211064 \pm 25800$ (range: 13149 to 436661) in ALL and 416339 \pm 55329 in AML (range: 35724 to 741641 ). AML showed significantly higher HLA I expression than ALL $\left(n_{\mathrm{AML}}=14, n_{\mathrm{ALL}}=21 ; p=0.0007\right)$. (b) Cellular cytotoxicity (BATDA europium release assay, Perkin Elmer) of freshly isolated $\mathrm{CD}_{6} 6^{+}$enriched and $\mathrm{CD}^{+}$depleted NK cells from healthy volunteer donors towards ALL (only 1 donor, $n_{\mathrm{ALL}}=21$ ) versus AML (2 different donors, $\left.n_{\mathrm{AML}}=14\right)$ blasts with and without IL2 prestimulation at E: T ratio 10:1 revealed significantly higher lysis in AML than ALL without IL2 prestimulation (filled symbols) and with IL2 prestimulation (blank symbols) $\left(p_{\mathrm{w} / \mathrm{o} \text { IL2 }}=0.0007 ; p_{\text {IL2 }}=0.0038\right)$. Comparing ALL versus AML lysis in single donor comparison also revealed significantly higher lysis for AML blasts. The ALL data was already published in Br J Haematology 2007 [11].

(Dako, Hamburg, Germany); polyclonal goat anti-mouse (Gt $\left.\mathrm{F}\left(\mathrm{ab}^{\prime}\right)_{2}, \mathrm{PE}\right)$ (Becton Dickinson). Quantitative analyses of HLA class I and HLA-E expression were done according to manufacturer's instructions (Qifikit, Dako). One antigen binding site was assumed per one antigen molecule. Mean Fluorescence Intensity Ratios (MFIR) were calculated by dividing the mean fluorescence signals from AML blasts by the corresponding isotype control. A ratio $>2$ was defined positive and a ratio $>10$ was defined highly positive. Analyses of flow cytometric data were performed using FCS Express 4.0 (De Novo Software, Glendale, CA, USA).

2.6. Cytotoxicity Assay. Cytolytic activity of NK cells was measured in a $2 \mathrm{~h}$ BATDA [bis(acetoxymethyl)2,2:6,2terpyridine-6,6-dicarboxylate] europium release assay. Cryopreserved primary childhood AML blasts and the erythroblastoid cell line K562 (M6 leukemia) were used as target cells. No enrichment of primary childhood AML blasts was done: purity $>80 \%$ blasts. K562 was used as positive control to exclude functional NK cell inactivity. Target cells (leukemic blasts) were labeled with $3 \mu \mathrm{L}$ of the fluorescence enhancing ligand BATDA (Perkin Elmer, Waltham, MA, USA) for $60 \mathrm{~min}$ at $37^{\circ} \mathrm{C}$. After five washing steps, the target cell suspension was adjusted to $2 \times 10^{5}$ cells/well and seeded into microplates (5000 cells/well). Four different effector to target $(\mathrm{E}: \mathrm{T})$ ratios were tested with and without IL2 preincubation overnight (Proleukin, Basel, Switzerland). The assays were done as published [16]. Specific lysis was calculated as follows: \%-specific lysis = (experimental release - spontaneous release)/(maximum release - spontaneous release) $* 100$.
2.7. Statistical Analysis. Analysis was done using GraphPad Prism Version 5.04. $p$ values $<0.05$ were considered significant. Unpaired and paired t-tests as well as Pearson's correlation coefficient were used. For the comparison of donor $\mathrm{A}$ and donor $\mathrm{B}$, the pairing considered the blasts (e.g., blast number 1-blast number 1 ); the comparing condition was the NK activity (specific lysis).

\section{Results}

3.1. HLA I and HLA-E Expression on Childhood AML Blasts. The mean HLA I expression was $416339 \pm 55329$ molecules per AML blast (range: 35724 to $741642 /$ cell) (Figure 1(a)). AML blasts showed higher expression of HLA class I compared to pediatric ALL blasts. The ALL data was already published in Br J Haematology 2007 [11]. In contrast, HLAE expression in childhood AML blasts was low (range: 0 to 2700 molecules/cell). Comparing NK cell mediated cytotoxicity without and with IL2 prestimulation revealed a higher susceptibility of AML blasts, despite higher mean expression of HLA I molecules per blast (Figure 1(b)).

3.2. Impact of HLA I Expression and KIR Ligand Mismatch on the Lysis of AML Blasts. There was no correlation of HLA I expression and NK cell mediated cytolysis of childhood AML blasts independent from $\mathrm{E}: \mathrm{T}$ ratio and without or with IL2 prestimulation $(n=14$, donors $\mathrm{A}$ and $\mathrm{B}, \mathrm{E}: \mathrm{T}$ $10: 1$, without IL2, Pearson $r=-0.06, p=0.83$; with IL2, $r=-0.11, p=0.70$ ) (Figures 2(a) and 2(c)). Furthermore, no correlation was found in single donor analysis. HLA-E expression was not correlated with blast lysis in donor A 


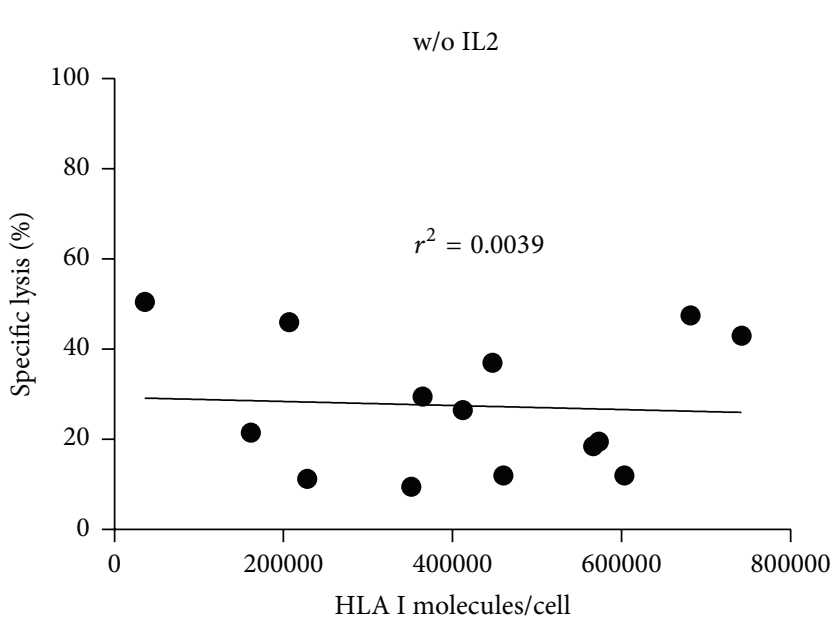

(a)

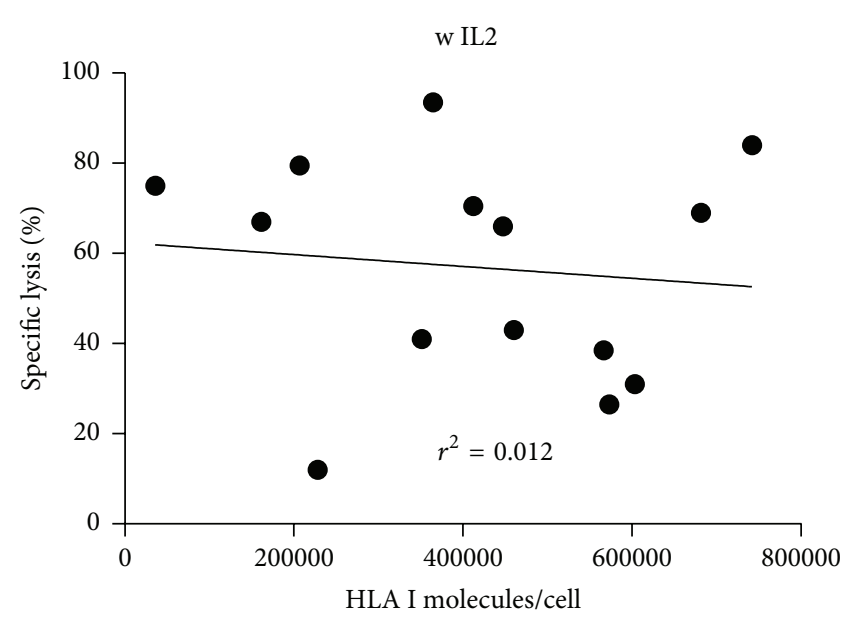

(c)

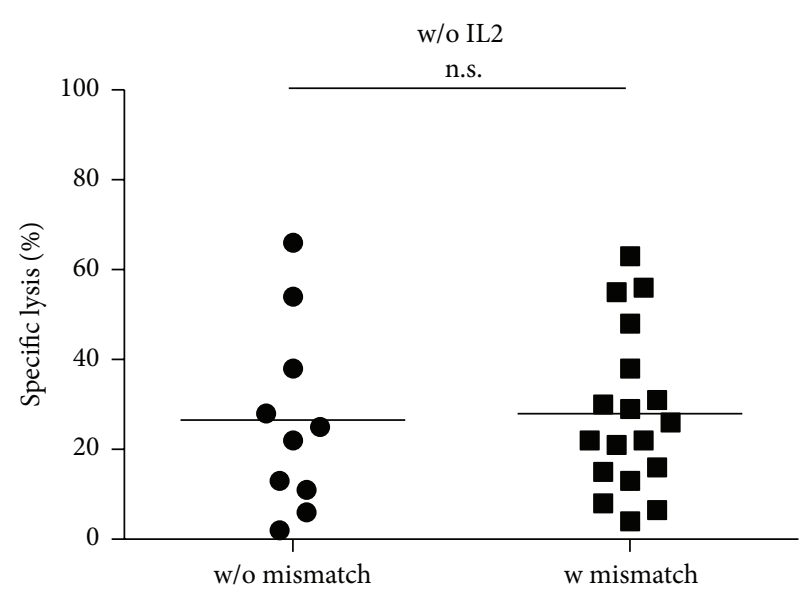

(b)

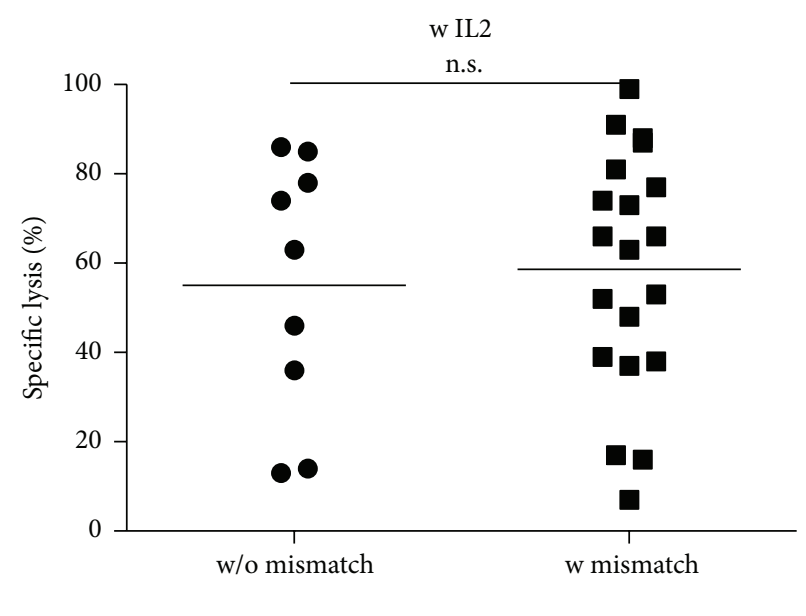

(d)

FIGURE 2: (a) Quantitative HLA I expression measured by Qifikit (Dako) was correlated to the mean NK cell mediated lysis (2 donors) of primary childhood AML blasts at E:T ratio $10: 1$. NK cells were obtained from two healthy volunteer donors. PBMCs were isolated from peripheral whole blood by density gradient centrifugation using Biocoll separating solution (Biochrom) followed by a two-step immunomagnetic CD56 ${ }^{+}$enrichment and subsequent $\mathrm{CD}^{+}$depletion. No correlation was found without IL2 prestimulation $\left(n_{\mathrm{AML}}=14\right.$; Pearson $r=-0.06, r^{2}=0.0039, p=$ n.s.). (b) Distribution of blast HLA type was C1/C1 $(n=5), \mathrm{C} 1 / \mathrm{C} 2(n=5)$, and C2/C2 $(n=4)$. KIR ligand-ligand match versus mismatch did not reveal any difference in specific lysis of primary childhood AML blasts $\left(n_{\mathrm{w} / \mathrm{o} \text { mismatch }}=10\right.$, $\left.n_{\text {mismatch }}=18 ; p=0.84\right)$. Donor A revealed a KIR ligand-ligand match versus mismatch proportion (3 to 11) and donor B revealed a KIR ligand-ligand match versus mismatch proportion (7 to 7). (c) No correlation was found with IL2 prestimulation at $\mathrm{E}: \mathrm{T}$ ratio $10: 1\left(n_{\mathrm{AML}}=14\right.$; Pearson $r=-0.11, r^{2}=0.012, p=$ n.s.). (d) There was no impact of KIR ligand-ligand match or mismatch on IL2 prestimulated NK cell mediated cytolysis of AML blasts.

or B in any condition (Figure S1 in Supplementary Material available online at http://dx.doi.org/10.1155/2015/473175).

The analysis of KIR ligand-ligand match versus mismatch revealed a proportion of ( 3 to 11 ) in donor $\mathrm{A}$ and (7 to 7 ) in donor $B$ with difference neither without nor with IL2 prestimulation (Figures 2(b) and 2(d)). Furthermore, no correlation was found in single donor analysis. Further analysis by subdividing into a KIR ligand match and mismatch group did not result in a correlation of specific lysis and quantitative HLA I expression in any group.

3.3. NK Cell Cytolysis of Childhood AML Blasts and K562 Cell Line. Mean lysis of $\mathrm{K} 562$ blasts at E: T ratio $10: 1$ in donors $A$ and $B$ without IL2 prestimulation was $67.2 \pm 6.0 \%$ and
$73.2 \pm 4.0 \%$ and with IL2 prestimulation was $82.1 \pm 4.5 \%$ and $81.8 \pm 4.7 \%$, respectively. There was no significant difference comparing the lysis ability of donors $\mathrm{A}$ and $\mathrm{B}$ in any $\mathrm{E}: \mathrm{T}$ ratio or by integrating the $\mathrm{E}: \mathrm{T}$ ratios $20: 1,10: 1,5: 1$, and $2.5: 1$ without and with IL2 prestimulation and there was no difference comparing the increase of lysis by IL2 (Figures S2 $\mathrm{A}, \mathrm{B}$, and C). IL2 significantly increased the lysis of K562 in both donors $\left(n_{\mathrm{A}}=9, p_{\mathrm{A}}<0.0001 ; n_{\mathrm{B}}=12, p_{\mathrm{B}}=\right.$ 0.0006 ) (Figures S2 D and E). No differences in susceptibility to NK cell mediated lysis depending on FAB classification were observed.

In the tested childhood AML blasts, donor B showed significantly higher lysis than donor $\mathrm{A}(n=14$, all ETs, $p=0.0029$ ) (Figure $3(\mathrm{a})$ ). At an $\mathrm{E}: \mathrm{T}$ ratio of $10: 1$, mean 


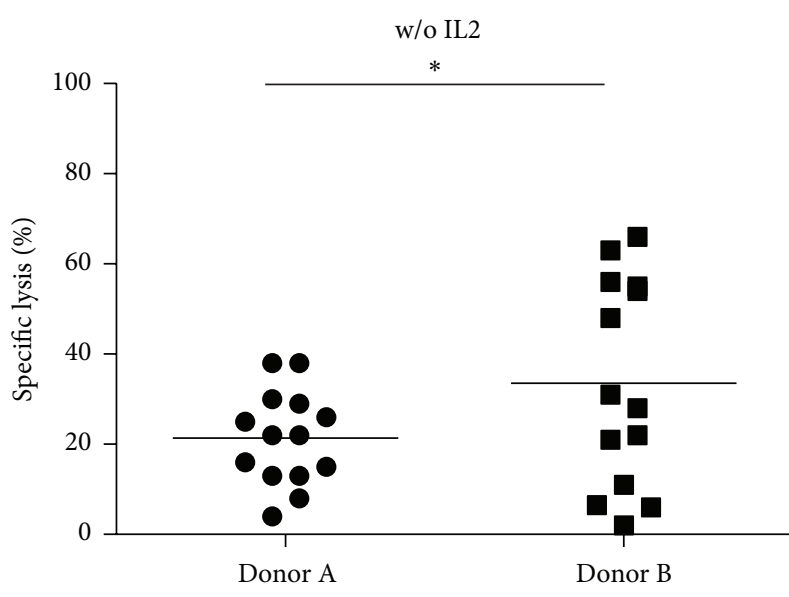

(a)

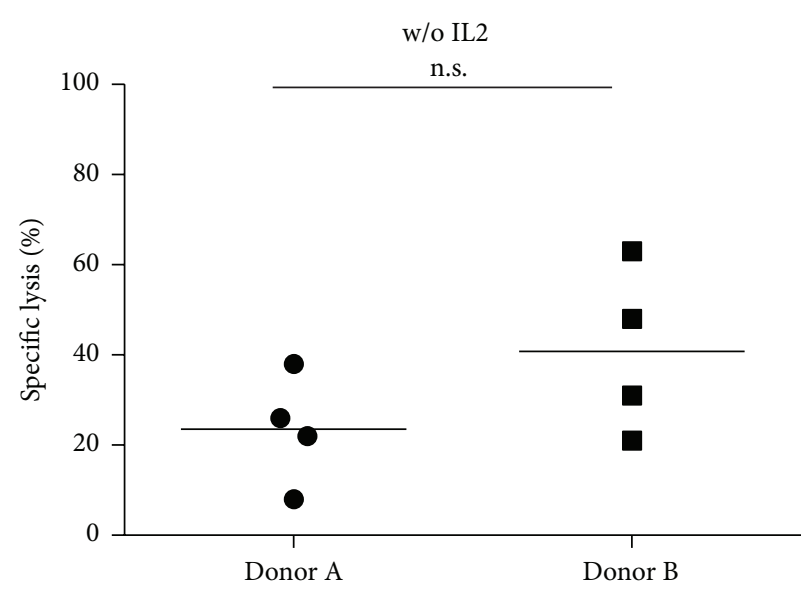

(b)

FIGURE 3: (a) Cytolysis of isolated NK cells comparing donor A (B content score 0) versus donor B (B content score 3) towards 14 primary childhood AML blasts at $\mathrm{E}: \mathrm{T}$ ratio $10: 1$. PBMCs were isolated from peripheral whole blood from two healthy volunteer donors A and B by density gradient centrifugation using Biocoll separating solution (Biochrom) followed by a two-step immunomagnetic CD56 ${ }^{+}$enrichment and subsequent $\mathrm{CD}^{+}$depletion. Donor B showed significantly higher lysis than donor $\mathrm{A}\left(n_{\mathrm{AML}}=14, p=0.038\right)$. (b) The analysis of blast lysis of blasts homozygous for $\mathrm{C} 2$ showed by trend a higher lysis of donor $\mathrm{B}\left(n_{\mathrm{C} 2 / 2}=4, p=0.06\right)$ applying the $\mathrm{E}: \mathrm{T}$ ratio $10: 1$. Donor $\mathrm{A}$ was KIR2DL1 positive and donor B was KIR2DL1 negative. KIR2DL1 is the corresponding KIR receptor for the C2 HLA group.

lysis was significantly higher in donor B than in donor A without IL2 prestimulation ( $21.4 \pm 2.8 \%$ versus $33.5 \pm 6.1 \%$, $n=14, p=0.038)$ but not with IL2 prestimulation $(56.1 \pm 6.1 \%$ versus $57.6 \pm 8.5 \%)$. The increase of lysis by IL2 was significant in both donors $\left(n=14, p_{\mathrm{A}}<0.0001\right.$, $\left.p_{\mathrm{B}}=0.0002\right)$ but was significantly higher in donor $\mathrm{A}$ versus donor $\mathrm{B}(n=14$, all ETs, $p=0.0035)$. There was no influence of KIR ligand mismatch between NK donor and AML blasts on specific lysis within each donor. The activating KIR2DS2 and KIR3DS1 encoded by donor B were not found to significantly influence NK mediated cytolysis in this setting of these experiments. Yet, donor B showed a higher lysis of C2 homozygous AML blasts than donor A without and with IL2 prestimulation. The comparison at E:T 10:1 was not significant $\left(n_{\mathrm{C} 2 / 2}=4, p_{\mathrm{w} / \mathrm{o} \text { IL2 }}=0.06\right)$ (Figure $\left.3(\mathrm{~b})\right)$ but was significantly higher comparing all ETs $\left(n_{\mathrm{C} 2 / 2}=4\right.$, all ETs, $\left.p_{\mathrm{w} / \mathrm{o} \mathrm{IL} 2}=0.008, p_{\mathrm{w} \text { IL2 }}=0.04\right)$. No difference was found for $\mathrm{C} 1$ homozygous AML blasts $\left(n_{\mathrm{C} 1 / 1}=5, p_{\mathrm{w} / \mathrm{o} \mathrm{IL} 2}=0.29\right.$, $\left.p_{\mathrm{w} \text { IL2 }}=0.102\right)$ and $\mathrm{C} 1 / \mathrm{C} 2$ heterozygous blasts $\left(n_{\mathrm{C} 1 / 2}=\right.$ $4, p_{\mathrm{w} / \mathrm{o} \text { IL2 }}=0.13, p_{\mathrm{w} \text { IL2 }}=0.83$ ) without and with IL2 prestimulation (Figure S3). The impact of the KIR ligandligand model published by the Perugia group (Velardi) in 2002 [8] did not reveal any differences in cytolysis of $\mathrm{C1} / \mathrm{Cl}$, $\mathrm{C} 1 / \mathrm{C} 2$, and $\mathrm{C} 2 / \mathrm{C} 2$ blasts for $\mathrm{C} 1 / \mathrm{C} 2$ donor $\mathrm{A}$ and $\mathrm{C} 1 / \mathrm{C} 1$ donor $\mathrm{B}$. The analyses included comparisons at all effector to target ratios $(20: 1,10: 1,5: 1$, and $2.5: 1)$ and pooled ET ratios (all 4 ETs).

3.4. Flow Cytometric Characterization of AML Blasts. NKG2D ligands ULBP1-4 were heterogeneously expressed on the tested AML blasts (Figure 4). The total mean MRFI of ULBP1-4 was $25.8 \pm 11.5$ ranging from negative to highly positive $(\mathrm{MRFI}=154$, Table S1). MICA and MICB were not detectable on the AML blasts. DNAM-1 ligand CD155 was low expressed but detectable on all blasts (MRFI $\geq 2$ ); CD112 was highly expressed in most AML blasts (MRFI $\geq 10$ ). The same pattern was found for LFA-1 (CD1la and CD18) as well as ICAM-3 (CD50) and LFA-3 (CD58). Heterogeneously expressed were ICAM-1 (CD54), SLAMF2 (CD48), and the FAS receptor CD95 (Table S2).

3.5. NKG2D Ligand Expression and NK Cell Cytolysis. Grouping the blasts by the mean MRFI of ULBP1-4 expression $(\mathrm{MRFI}=6.6)$ resulted in two groups with 7 blasts each. The lysis of the NKG2DL ${ }^{\text {high }}$ group was higher than cytolysis of the NKG2DL $\mathrm{N}_{\text {low }}$ group without IL2 but was not significant at $\mathrm{E}: \mathrm{T} 10: 1, p=0.11$ (Figure 5(a)). Comparing all effector to target ratios at once showed significantly higher lysis of the NKG2DL ${ }^{\text {high }}$ group $(n=14$, all ETs, $p=0.0111)$. With IL2 prestimulation, no difference between the cytolysis of NKG2DL ${ }^{\text {high }}$ and NKG2DL low $(n=14$, all ETs, $p=0.52)$ was found. Furthermore, we grouped the blasts into HLA $\mathrm{I}_{\mathrm{low}}$ and HLA I $^{\text {high }}$. Blasts with HLA I molecules higher than or within the range of the mean minus standard deviation were defined as HLA I ${ }^{\text {high }}$ blasts, whereas blasts with HLA I below the mean expression minus standard deviation were defined as HLA $\mathrm{I}_{\text {low }}$ blasts. Analyzing the HLA I ${ }^{\text {high }}$ blasts only, NK cytolysis showed significant positive correlation with NKG2D ligand expression (Pearson $r=0.78, p=0.0076$ ) (Figure 5(b)). Obversely excluding NKG2DL ${ }^{\text {high }}$ blasts with an absolute MRFI >10 cytolytic activity inversely correlated with HLA I expression (Pearson $r=-0.68, p=0.04$ ) (Figure 5(c)).

\section{Discussion}

Improvement in the treatment of childhood AML has led to an overall survival of $60 \%$ [1]. Failure of treatment comprises relapse in $30-40 \%$ of patients and treatment related mortality. Relapsed patients face a clearly reduced overall survival of 

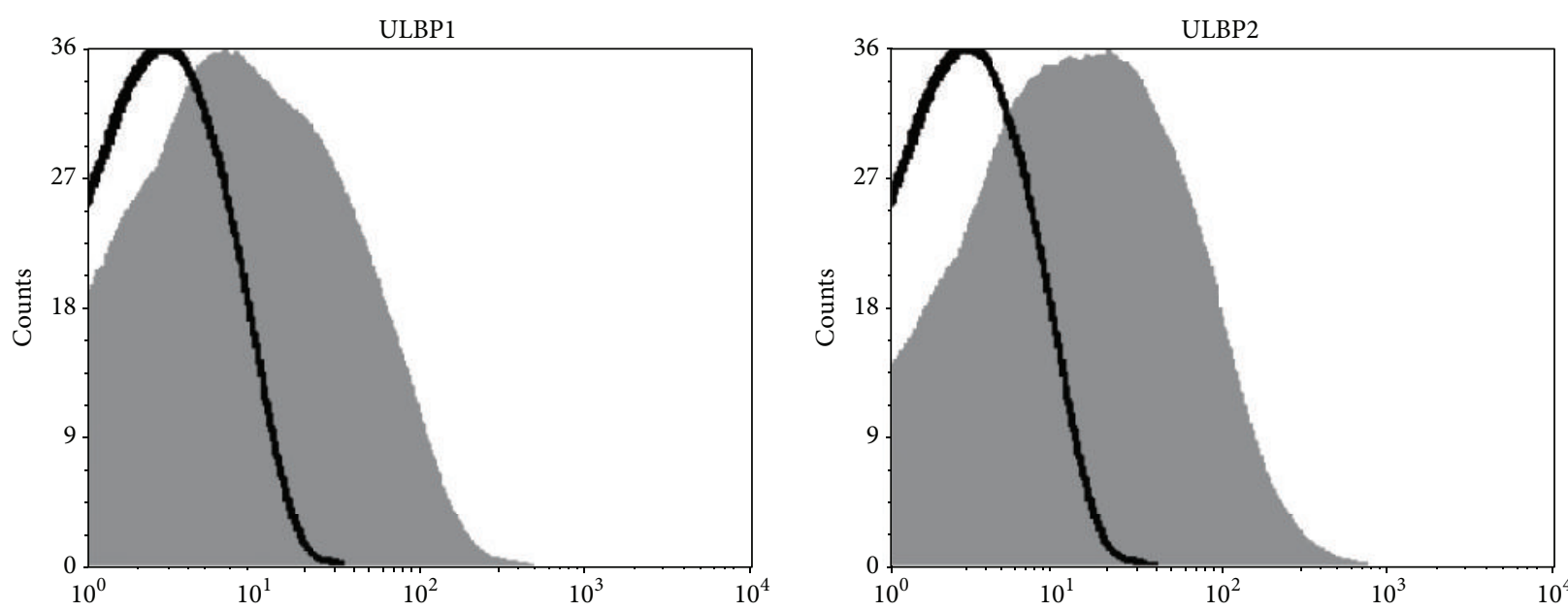

AML-2
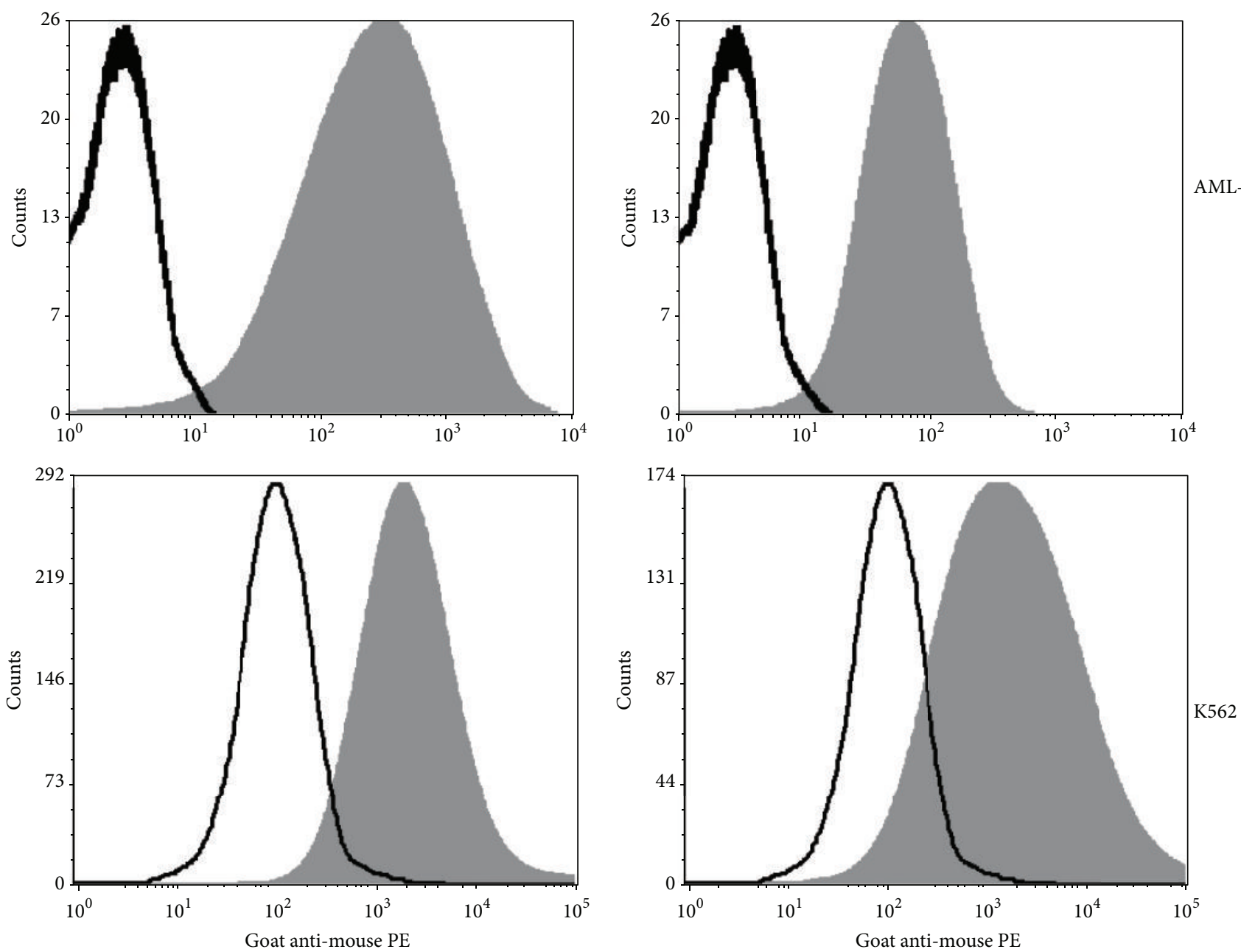

FIGURE 4: NKG2D ligand expression of the primary childhood AML blasts, AML-2 and AML-9, and the erythroblastoid cell line K562. Cells were incubated with unlabeled mouse anti-human ULBP1 and ULBP2 antibody and incubated in a second step with a PE labelled secondary goat anti-mouse antibody and measured on a FACSCalibur flow cytometer. Isotype control corresponds to the black line; the ULBP1 and ULBP2 positivity of the cells is displayed in shaded grey. In AML-2, 51.34\% of the cells were ULBP1 positive and 49.40\% were ULBP2 positive. In AML-9, 95.74\% of the cells were ULBP1 positive and 95.12\% were ULBP2 positive. In K562, 91.34\% were ULBP1 positive and $86.14 \%$ were ULBP2 positive. The percentage of positive ULBP1 and ULBP2 cells was obtained by histogram subtraction method. The Median Fluorescence Intensity Ratio (MFIR) for AML-2 was 2.82 for ULBP1 and 3.34 for ULBP2; for AML-9, it was 117.67 for ULBP1 and 28.35 for ULBP2; for K562, it was 19.28 for ULBP1 and 15.35 for ULBP2. MFIR was calculated by the MFI goat anti-mouse PE divided by the MFI isotype control. 


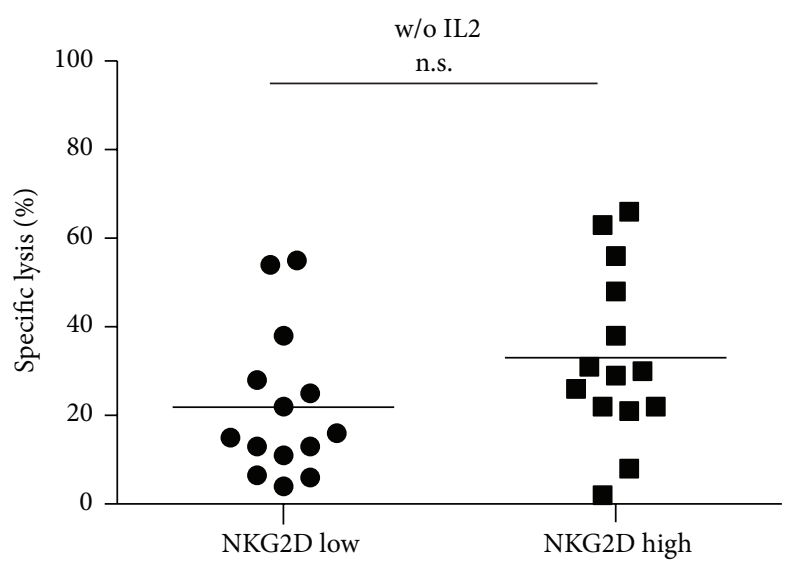

(a)

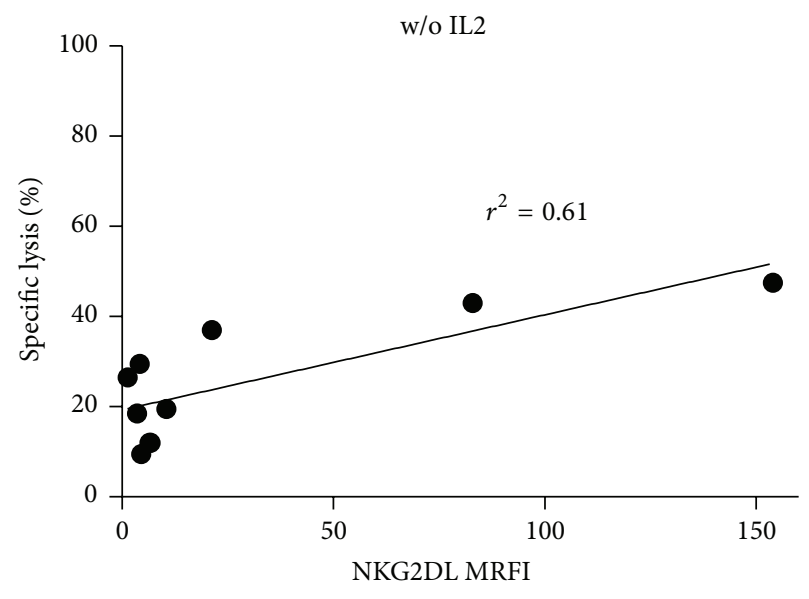

(b)

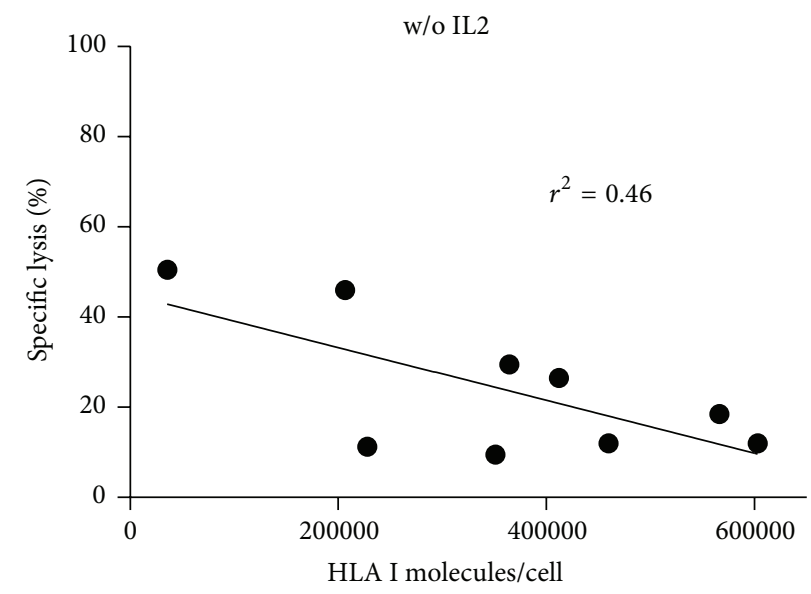

(c)

FIGURE 5: NKG2DL and HLA I expression importantly influence NK cell activation. (a) NKG2DL expression was measured semiquantitatively by calculating the MFIR (Mean Fluorescence Intensity Ratio). The blasts were grouped by the mean MFIR of ULBP1-4 into NKG2DL low and NKG2DL ${ }^{\text {high }}$ blasts (mean MFIR 6.6; NKG2DL low $_{<}<6.6$, NKG2DL ${ }^{\text {high }}>6.6$ ). NKG2DL ${ }^{\text {high }}$ blasts were lysed by trend higher than NKG2DL $\mathrm{N}_{\text {low }}$ blasts including the $\mathrm{E}: \mathrm{T}$ ratio $10: 1$ of two healthy volunteer donors by immunomagnetic $\mathrm{CD} 56^{+}$enriched and $\mathrm{CD} 3^{+}$depleted $\mathrm{NK}$ cells $\left(n_{\text {high }}=7, n_{\text {low }}=7 ; p=0.11\right)$. (b) The blasts were grouped by HLA I expression. HLA I ${ }^{\text {high }}$ blasts were defined by HLA I molecules per cell within the range of the mean and standard deviation (SD) or higher; the HLA $\mathrm{I}_{\text {low }}$ blasts were below the mean minus SD. The NKG2DL expression significantly correlated to NK cell mediated cytolysis of two healthy volunteer donors in the HLA I ${ }^{\text {high }}$ blast group at E : T ratio $10: 1$

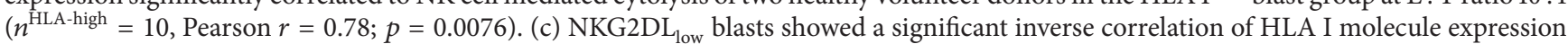
per cell and NK cell mediated cytolysis of two healthy volunteer donors at E: T ratio $10: 1\left(n_{\text {NKG2D-low }}=9\right.$, Pearson $\left.r=-0.68 ; p=0.0426\right)$.

16 to $42 \%$ [2] and are often in need for an allogeneic HSCT [17]. In HSCT, NK cells have been identified to play a crucial role in relapse-free survival [14]. In particular alloreactive GVL reactions have been demonstrated to reduce relapse rates in adult AML and pediatric ALL after HSCT [8, 15, $18,19]$. Three original different models have been established to predict NK alloreactivity starting with the ligand-ligand mismatch defined by the Perugia group if the donor has a HLA ligand that is absent in the recipient $[8,9]$, the Memphis model defined by the incompatibility of donor KIR receptor and recipient HLA ligand [20], and the Stanford KIR haplotype model defined by presence of activating KIR receptors [21]. For pediatric ALL, several factors have been described that influence NK susceptibility of ALL blasts like quantitative HLA class I expression and KIR receptor ligand mismatch between NK cells and blasts in graft versus host direction [11, 12] or expression of DNAM-1 ligands [22].

Here, we aimed at investigating in vitro the factors which may influence the NK mediated cytolysis of primary childhood AML blasts in a HLA mismatched model. We found that ALL and AML showed heterogeneous expression of HLA I with significantly higher expression (twice as high) in AML than ALL (Figure 1(a)). The ALL data was already published in Br J Haematology 2007 [11]. Despite this observation, NK cell cytolysis of AML was significantly higher than in tested ALL blasts (Figure 1(b)) indicating that proactivating factors such as DNAM-1 ligands and NKG2D ligands are involved in the cytolysis of AML blasts [23, 24].

In our tested pediatric AML blasts, the capability of lysing the blasts was increased in donor B (Figure 3(a)). Multidimensional differences included HLA type and KIR 
genotype. In the condition with IL2 prestimulation, there was no difference between donor A and donor B (Figure S4 A). This might be a hint that cytokine activated NK cells, irrespective of the donor, can overcome inhibition of target cells by shifting the balance of regulation towards NK cell activation [25]. Whereas there was no difference in cytolysis regarding KIR ligand-ligand match versus mismatch and KIR $\mathrm{RL}$ match/mismatch regarding all blasts at once, subgrouping into blast HLA genotype $\mathrm{C} 1$ group and blast HLA genotype C2 group revealed increased lysis of donor B in blasts homozygous for HLA C2 in comparison to donor A without and with IL2 prestimulation (Figure 3(b), Figures S4 and S5 B) [21]. Donor B lacked KIR2DL1 (KIR2DL1 gene not encoded), which is the corresponding KIR receptor for HLA C2. Thus homozygous C2 blasts express an inhibitory HLA I ligand for which donor $\mathrm{B}$ does not have a corresponding KIR receptor and cannot be inhibited hereby. A similar observation has been shown to be clinically relevant in T cell depleted haploidentical HSCT. The risk of relapse in ALL and AML was significantly determined by the reconstitution of NK KIR receptors [26].

In consequence, there must be other factors leading to sufficient AML blast lysis by NK cells $[23,25]$. In vivo and also proven in vitro, AML blasts hamper NK cell function by various mechanisms including $\mathrm{T}_{\text {reg }}$ induction, shedding of soluble NKG2D ligands (MIC and ULBP molecules), and direct cellular interaction inducing unfavorable KIR phenotype and reduction of proactivating NK cell receptors [13]. For instance, the high expression of DNAM-1 ligands CD112 and CD155 induces the downregulation of DNAM-1 NK coreceptor by receptor-ligand crosslinking [27]. Moreover, natural cytotoxicity receptors (NCRs) play a crucial role in the recognition and elimination of AML. The NCR dull immunophenotype, most likely induced by cellular interaction of AML blasts and NK cells, is reversible during absence of AML blasts in complete remission and is associated with poor outcome, demonstrating the plasticity of NK cell receptor landscape and function by the close interaction with AML [28].

Two well-characterized and strong mechanisms of NK cell activation are NKG2D- and DNAM-1 signaling [29]. In ALL, blasts do express low density of NKG2D ligands compared to AML and CLL [30]. In pediatric ALL, blasts show significant higher NKG2DL expression than adult ALL blasts [22]. There is only little data published on pediatric AML. In contrast to childhood ALL blasts (own data not shown), childhood AML blasts heterogeneously expressed NKG2D ligands, ranging from low to very high levels of ULBP1-4 expression, with all blasts being negative for MICA and MICB (Figure 4 and Table S1). This confirms and extends the finding in adult AML, at least a proportion of AML blasts being negative for MICA and MICB also in childhood AML $[24,31]$. In our tested blasts, $64 \%$ were at least low positive for any NKG2D ligand and 28\% were highly positive facilitating grouping the blasts into $\mathrm{NKG}_{2} \mathrm{DL}_{\text {low }}$ and $\mathrm{NKG} 2 \mathrm{DL}{ }^{\text {high }}$ phenotypes. DNAM-1 ligands were homogeneously expressed (Table S2) and thus were not suitable to subgroup the blasts and to explain the different lysis of the tested AML blasts, even though DNAM-1 triggering is important in the lysis of several tumor targets including AML $[23,32]$. By subgrouping the blasts according to NKG2DL expression, a difference of cytolysis was revealed (Figure 5(a) and Figure S6), strongly indicating a major impact of NKG2D on NK cell mediated lysis of childhood AML blasts [24, 25, 30]. This hypothesis was further supported by a significant inverse correlation of HLA I expression and NK cell mediated cytolysis of NKG2DL $\mathrm{N}_{\text {low }}$ blasts (Figure 5(c)). Conversely, a significant positive correlation was found for NKG2DL expression within the HLA $\mathrm{I}^{\text {high }}$ blasts (Figure 5(b)). In conclusion, both well-established prostimulatory factors of NK cell activation were confirmed: HLA I reduction and NKG2DL positivity determined NK cell mediated lysis of childhood AML blasts. Moreover, NKG2DL high expression was strong enough to override NK cell inhibition by HLA I expression. Obversely, blast 14 showed extremely low HLA I expression and was lysed very well despite lacking NKG2DL expression.

These results imply that, for immunotherapeutical approaches recruiting NK cells, a characterization of target cells including HLA I typing and HLA I quantification and characterization of surface markers on the blasts might help estimate how sensitive the targets might be for NK cells. Furthermore, characterization of the donor with regard to HLA typing, KIR genotyping, and KIR RL mismatch can possibly improve donor selection of NK cell immunotherapy or HSCT. According to the minimized in vitro cytolytic differences between donor $\mathrm{A}$ and donor $\mathrm{B}$ after cytokine stimulation with IL2 and the significant increase in cytolytic activity ex vivo, NK cell transfer in lymphodepletion after chemotherapy or in vivo NK cell stimulation by subcutaneous low-dose and long-term IL2 application should be considered as treatment options in AML patients $[3,33,34]$. To counteract escape mechanism of AML like downregulation of NKG2D ligands [13], NKG2D receptor induction in NK cells by ex vivo expansion $[35,36]$ or in vivo expansion plus activation by applied cytokines $[34,37]$, and on the other hand induction of NKG2D ligands on AML target cells by all-trans retinoic acid, the histone deacetylase inhibitor sodium valproate or spironolactone might increase clinically relevant $\mathrm{NK}$ mediated antitumor effect [38-41]. In conclusion, the inhibition of NK cells in childhood AML through high HLA I expression can be overridden by prostimulatory NKG2D signaling. The increased knowledge on childhood AML recognition and cytolysis by NK cells will aid in designing novel NK celltargeting and optimizing immunotherapy approaches for the treatment of AML.

\section{Conflict of Interests}

The authors declare that there is no conflict of interests regarding the publication of this paper.

\section{Acknowledgments}

This work was supported by grants from the Stiftung für krebskranke Kinder Tübingen e.V. and the Stefan-MorschStiftung to Rupert Handgretinger and the Jose-Carreras 
Leukaemia Foundation to Matthias Pfeiffer and Rupert Handgretinger, as well as by grants from the Deutsche Forschungsgemeinschaft (SFB685), the BMBF, and the Reinhold Beitlich Stiftung to Peter Lang.

\section{References}

[1] G. J. L. Kaspers and U. Creutzig, "Pediatric acute myeloid leukemia: international progress and future directions," Leukemia, vol. 19, no. 12, pp. 2025-2029, 2005.

[2] J. Abrahamsson, N. Clausen, G. Gustafsson et al., "Improved outcome after relapse in children with acute myeloid leukaemia," British Journal of Haematology, vol. 136, no. 2, pp. 229-236, 2007.

[3] J. E. Rubnitz, H. Inaba, R. C. Ribeiro et al., "NKAML: a pilot study to determine the safety and feasibility of haploidentical natural killer cell transplantation in childhood acute myeloid leukemia," Journal of Clinical Oncology, vol. 28, no. 6, pp. 955959, 2010.

[4] E. Vivier, D. H. Raulet, A. Moretta et al., "Innate or adaptive immunity? The example of natural killer cells," Science, vol. 331, no. 6013, pp. 44-49, 2011.

[5] B. A. Pierson and J. S. Miller, "CD56+bright and CD56+dim natural killer cells in patients with chronic myelogenous leukemia progressively decrease in number, respond less to stimuli that recruit clonogenic natural killer cells, and exhibit decreased proliferation on a per cell basis," Blood, vol. 88, no. 6, pp. 2279-2287, 1996.

[6] F. Tajima, T. Kawatani, A. Endo, and H. Kawasaki, "Natural killer cell activity and cytokine production as prognostic factors in adult acute leukemia," Leukemia, vol. 10, no. 3, pp. 478-482, 1996.

[7] M. W. Lowdell, R. Craston, D. Samuel et al., "Evidence that continued remission in patients treated for acute leukaemia is dependent upon autologous natural killer cells," British Journal of Haematology, vol. 117, no. 4, pp. 821-827, 2002.

[8] L. Ruggeri, M. Capanni, E. Urbani et al., "Effectiveness of donor natural killer cell alloreactivity in mismatched hematopoietic transplants," Science, vol. 295, no. 5562, pp. 2097-2100, 2002.

[9] L. Ruggeri, A. Mancusi, M. Capanni et al., "Donor natural killer cell allorecognition of missing self in haploidentical hematopoietic transplantation for acute myeloid leukemia: challenging its predictive value," Blood, vol. 110, no. 1, pp. 433-440, 2007.

[10] W. Leung, "Use of NK cell activity in cure by transplant," British Journal of Haematology, vol. 155, no. 1, pp. 14-29, 2011.

[11] M. Pfeiffer, M. Schumm, T. Feuchtinger, K. Dietz, R. Handgretinger, and P. Lang, "Intensity of HLA class I expression and KIR-mismatch determine NK-cell mediated lysis of leukaemic blasts from children with acute lymphatic leukaemia," British Journal of Haematology, vol. 138, no. 1, pp. 97-100, 2007.

[12] T. Feuchtinger, M. Pfeiffer, A. Pfaffle et al., "Cytolytic activity of NK cell clones against acute childhood precursor-B-cell leukaemia is influenced by HLA class I expression on blasts and the differential KIR phenotype of NK clones," Bone Marrow Transplantation, vol. 43, no. 11, pp. 875-881, 2009.

[13] E. Lion, Y. Willemen, Z. N. Berneman, V. F. I. Van Tendeloo, and E. L. J. Smits, "Natural killer cell immune escape in acute myeloid leukemia," Leukemia, vol. 26, no. 9, pp. 2019-2026, 2012.

[14] S. Cooley, D. J. Weisdorf, L. A. Guethlein et al., "Donor selection for natural killer cell receptor genes leads to superior survival after unrelated transplantation for acute myelogenous leukemia," Blood, vol. 116, no. 14, pp. 2411-2419, 2010.

[15] S. U. Michaelis, M. Mezger, M. Bornhäuser et al., "KIR haplotype B donors but not KIR-ligand mismatch result in a reduced incidence of relapse after haploidentical transplantation using reduced intensity conditioning and CD3/CD19-depleted grafts," Annals of Hematology, vol. 93, no. 9, pp. 1579-1586, 2014.

[16] P. Lang, K. Barbin, T. Feuchtinger et al., "Chimeric CD19 antibody mediates cytotoxic activity against leukemic blasts with effector cells from pediatric patients who received T-celldepleted allografts," Blood, vol. 103, no. 10, pp. 3982-3985, 2004.

[17] G. J. L. Kaspers, M. Zimmermann, D. Reinhardt et al., "Improved outcome in pediatric relapsed acute myeloid leukemia: results of a randomized trial on liposomal daunorubicin by the international BFM study group," Journal of Clinical Oncology, vol. 31, no. 5, pp. 599-607, 2013.

[18] L. Oevermann, S. U. Michaelis, M. Mezger et al., "KIR B haplotype donors confer a reduced risk for relapse after haploidentical transplantation in children with all," Blood, vol. 124, no. 17, pp. 2744-2747, 2014.

[19] A. Velardi, L. Ruggeri, and A. Mancusi, "Killer-cell immunoglobulin-like receptors reactivity and outcome of stem cell transplant," Current Opinion in Hematology, vol. 19, no. 4, pp. 319-323, 2012.

[20] W. Leung, R. Iyengar, V. Turner et al., "Determinants of antileukemia effects of allogeneic NK cells," Journal of Immunology, vol. 172, no. 1, pp. 644-650, 2004.

[21] K. L. McQueen, K. M. Dorighi, L. A. Guethlein, R. Wong, B. Sanjanwala, and P. Parham, "Donor-recipient combinations of group A and B KIR haplotypes and HLA class I ligand affect the outcome of HLA-matched, sibling donor hematopoietic cell transplantation," Human Immunology, vol. 68, no. 5, pp. 309323, 2007.

[22] G. F. Torelli, N. Peragine, S. Raponi et al., "Recognition of adult and pediatric acute lymphoblastic leukemia blasts by natural killer cells," Haematologica, vol. 99, no. 7, pp. 1248-1254, 2014.

[23] D. Pende, G. M. Spaggiari, S. Marcenaro et al., "Analysis of the receptor-ligand interactions in the natural killer-mediated lysis of freshly isolated myeloid or lymphoblastic leukemias: evidence for the involvement of the Poliovirus receptor (CD155) and Nectin-2 (CD112)," Blood, vol. 105, no. 5, pp. 2066-2073, 2005.

[24] H. R. Salih, H. Antropius, F. Gieseke et al., "Functional expression and release of ligands for the activating immunoreceptor NKG2D in leukemia," Blood, vol. 102, no. 4, pp. 1389-1396, 2003.

[25] S. Verheyden and C. Demanet, "NK cell receptors and their ligands in leukemia," Leukemia, vol. 22, no. 2, pp. 249-257, 2008.

[26] M. M. Pfeiffer, T. Feuchtinger, H.-M. Teltschik et al., "Reconstitution of natural killer cell receptors influences natural killer activity and relapse rate after haploidentical transplantation of T- and B-cell depleted grafts in children," Haematologica, vol. 95, no. 8, pp. 1381-1388, 2010.

[27] C. J. Chan, M. J. Smyth, and L. Martinet, "Molecular mechanisms of natural killer cell activation in response to cellular stress," Cell Death and Differentiation, vol. 21, no. 1, pp. 5-14, 2014.

[28] J. Hilpert, L. Grosse-Hovest, F. Grünebach et al., "Comprehensive analysis of NKG2D ligand expression and release in leukemia: implications for NKG2D-mediated NK cell responses," The Journal of Immunology, vol. 189, no. 3, pp. 13601371, 2012. 
[29] P. Nowbakht, M.-C. S. Ionescu, A. Rohner et al., "Ligands for natural killer cell-activating receptors are expressed upon the maturation of normal myelomonocytic cells but at low levels in acute myeloid leukemias," Blood, vol. 105, no. 9, pp. 3615-3622, 2005.

[30] M. Pfeiffer, G. Seitz, P. Ruck et al., "CD155 is involved in NK-cell mediated lysis of human hepatoblastoma in vitro," Frontiers in Bioscience-Elite, vol. 3, no. 4, pp. 1456-1466, 2011.

[31] M. M. Pfeiffer, M. Schumm, I. Müller, R. Handgretinger, and P. Lang, "IL-15-stimulated CD3/CD19-depleted stem-cell boosts in relapsed pediatric patients after haploidentical SCT," Leukemia, vol. 26, no. 11, pp. 2435-2439, 2012.

[32] P. Schlegel, H.-M. Teltschik, M. Pfeiffer et al., "Long-term IL2 therapy after transplantation of $\mathrm{T}$ cell depleted stem cells from alternative donors in children," Best Practice and Research: Clinical Haematology, vol. 24, no. 3, pp. 443-452, 2011.

[33] H. Fujisaki, H. Kakuda, N. Shimasaki et al., "Expansion of highly cytotoxic human natural killer cells for cancer cell therapy," Cancer Research, vol. 69, no. 9, pp. 4010-4017, 2009.

[34] N. Peragine, G. F. Torelli, P. Mariglia et al., "Immunophenotypic and functional characterization of ex vivo expanded natural killer cells for clinical use in acute lymphoblastic leukemia patients," Cancer Immunology, Immunotherapy, vol. 64, no. 2, pp. 201-211, 2015.

[35] J. S. Miller, "Therapeutic applications: natural killer cells in the clinic," Hematology/The Education Program of the American Society of Hematology, vol. 2013, no. 1, pp. 247-253, 2013.

[36] M. M. Pfeiffer, H. Burow, S. Schleicher, R. Handgretinger, and P. Lang, "Influence of histone deacetylase inhibitors and DNAmethyltransferase inhibitors on the NK cell-mediated lysis of pediatric B-lineage leukemia," Frontiers in Oncology, vol. 3, article 99, 2013.

[37] W.-H. Leung, Q. P. Vong, W. Lin, L. Janke, T. Chen, and W. Leung, "Modulation of NKG2D ligand expression and metastasis in tumors by spironolactone via RXR $\gamma$ activation," The Journal of Experimental Medicine, vol. 210, no. 12, pp. 26752692, 2013.

[38] A. Poggi, S. Catellani, A. Garuti, I. Pierri, M. Gobbi, and M. R. Zocchi, "Effective in vivo induction of NKG2D ligands in acute myeloid leukaemias by all-trans-retinoic acid or sodium valproate," Leukemia, vol. 23, no. 4, pp. 641-648, 2009.

[39] S. Diermayr, H. Himmelreich, B. Durovic et al., "NKG2D ligand expression in AML increases in response to HDAC inhibitor valproic acid and contributes to allorecognition by NK-cell lines with single KIR-HLA class I specificities," Blood, vol. 111, no. 3, pp. 1428-1436, 2008.

[40] A. Poggi, S. Catellani, A. Garuti, I. Pierri, M. Gobbi, and M. R. Zocchi, "Effective in vivo induction of NKG2D ligands in acute myeloid leukaemias by all-trans-retinoic acid or sodium valproate," Leukemia, vol. 23, no. 4, pp. 641-648, 2009.

[41] S. Diermayr, H. Himmelreich, B. Durovic et al., "NKG2D ligand expression in AML increases in response to HDAC inhibitor valproic acid and contributes to allorecognition by NK-cell lines with single KIR-HLA class I specificities," Blood, vol. 111, no. 3, pp. 1428-1436, 2008. 


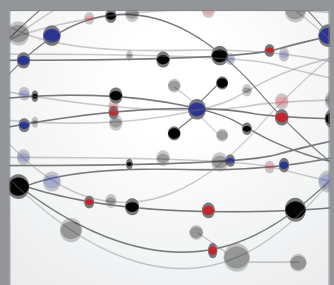

The Scientific World Journal
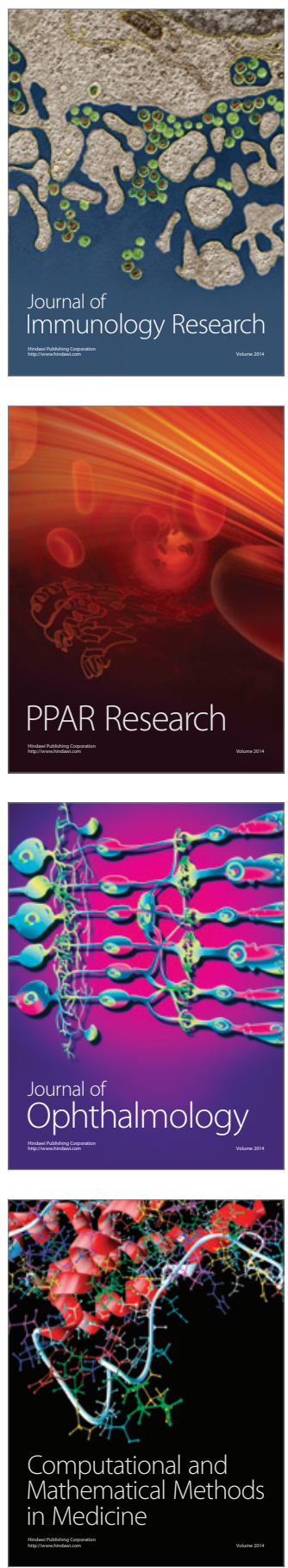

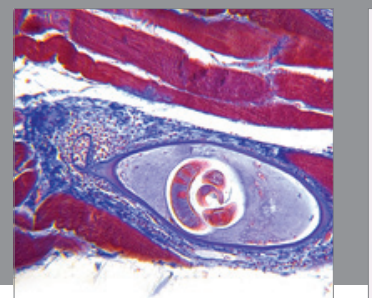

Gastroenterology

Research and Practice
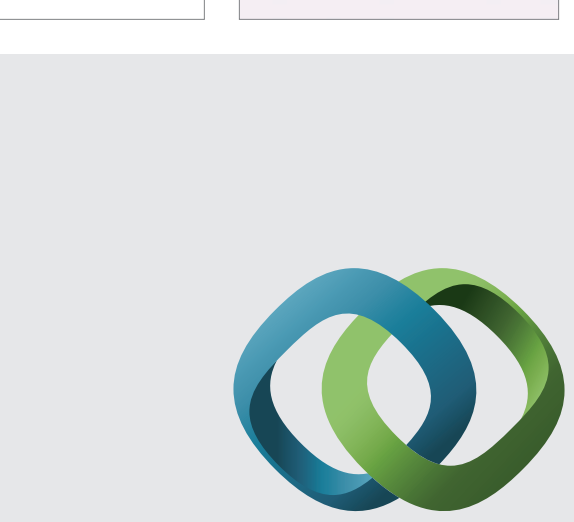

\section{Hindawi}

Submit your manuscripts at

http://www.hindawi.com
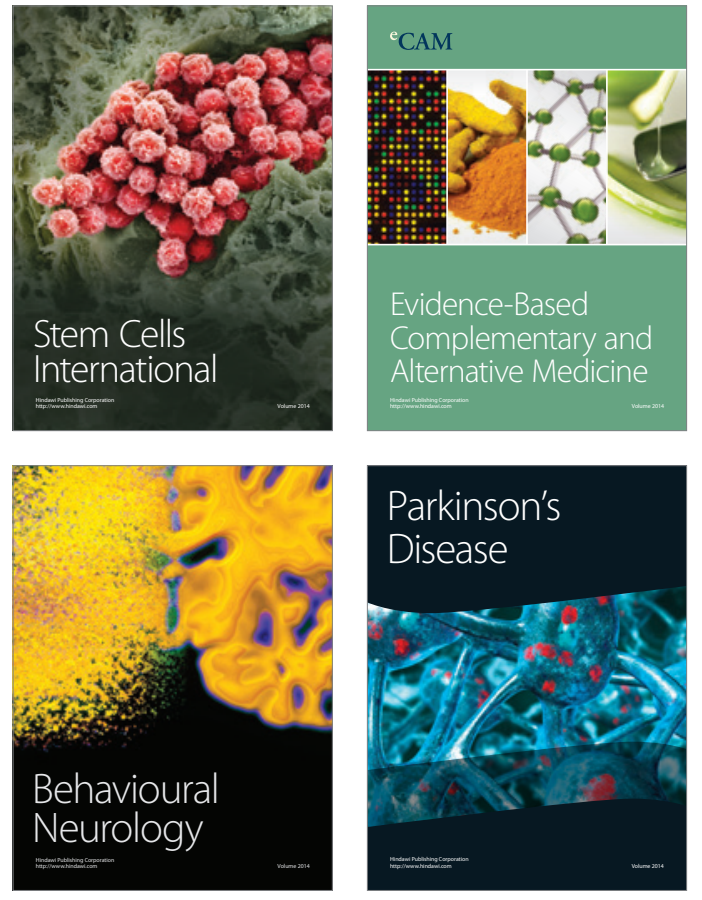
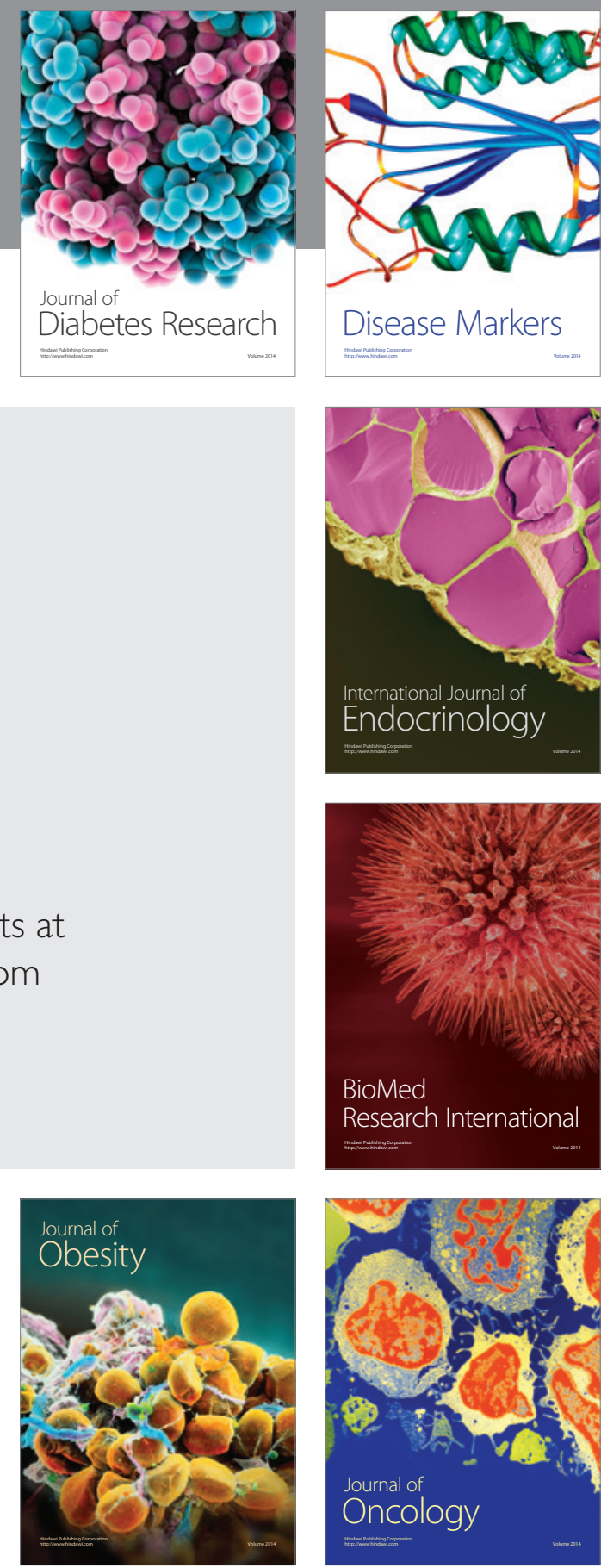

Disease Markers
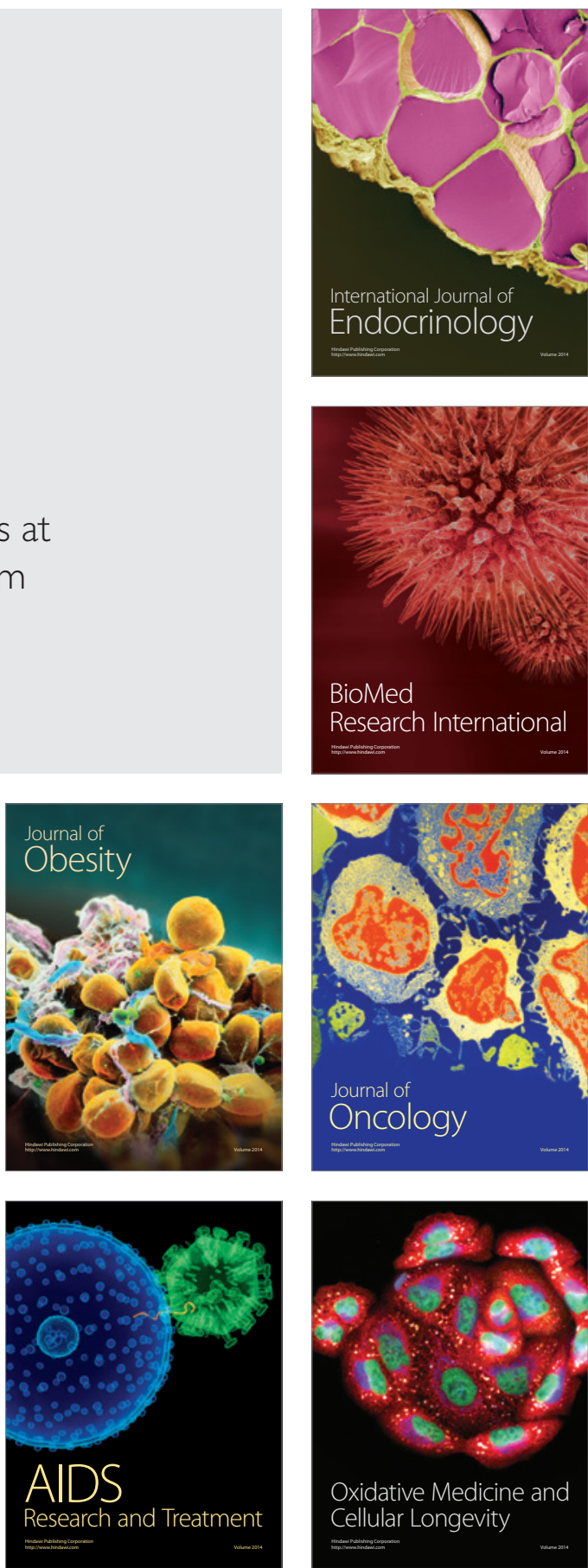